\title{
Alcoholic Marriage: Later Start, Sooner End
}

\author{
Mary Waldron, Andrew C. Heath, Michael T. Lynskey, Kathleen K. Bucholz, \\ Pamela A. F. Madden, and Nicholas G. Martin
}

\begin{abstract}
Background: Although associations between drinking behavior and marital status are well documented, timing of marital transitions as a function of alcohol use or disorder has received limited empirical attention.

Methods: We examine the relationship between lifetime history of alcohol dependence (AD) and timing and survival of first marriages in a sample of 3,575 female and 1,845 male adult Australian twins born mostly between 1940 and 1964. Survival analyses were conducted using Cox proportional hazards regression models.

Results: Results indicate moderate delays in marriage associated with AD for both women and men. Among ever-married respondents, AD was strongly predictive of early separation, with similar effects observed for women and men. Heritable sources of covariation were also documented. For women, genetic influences shared between early-onset AD and marital timing were found. Genetic influences shared between AD and marital survival were observed for women without regard to onset and for men with later-onset $\mathrm{AD}$.

Conclusions: Results confirm the importance of $\mathrm{AD}$ as a predictor of both timing and survival of first marriages, with genetic influences contributing to observed associations.
\end{abstract}

Key Words: Alcohol Dependence, Marital Onset, Marital Survival, Genetic Risks.

$T$ HE RELATIONSHIP BETWEEN marriage and drinking behavior is a topic of much interest in both alcohol and broader health literatures. Higher rates of heavy and problem drinking are consistently observed among nevermarried and divorced individuals, compared to the continuously married (e.g., Chilcoat and Breslau, 1996; Hajema and Knibbe, 1998; Temple et al., 1991; Wilsnack et al., 1984). While questions remain, researchers generally agree that two processes largely account for alcohol-related differences in marital status - nonrandom selection into (and out of) marriage as a function of prior use and a "marriage effect" (Bachman et al., 1997a; Leonard and Rothbard, 1999) related to changing roles and responsibilities associated with marriage.

Young adults who are heavy drinkers are less likely to marry than either abstainers or light drinkers (Chilcoat and Breslau, 1996; Power and Estaugh, 1990; Wilsnack et al., 1991). At the same time, drinking decreases among

From the School of Education (MW), Indiana University, Bloomington, Indiana; Department of Psychiatry ( $M W, A C H, M T L, K K B$, PAFM), Midwest Alcoholism Research Center, Washington University School of Medicine, St Louis, Missouri; and Genetic Epidemiology Unit (NGM), Queensland Institute of Medical Research, Brisbane, Australia.

Received for publication April 3, 2010; accepted September 15, 2010.

Reprint requests: Mary Waldron, PhD, Department of Counseling and Educational Psychology, School of Education, Indiana University, 201 N. Rose Avenue, Bloomington, 47405 IN; Tel.: 812-856-8334; Fax:812-856-8333; E-mail: mwaldron@indiana.edu

Copyright (C) 2011 by the Research Society on Alcoholism.

DOI: 10.1111/j.1530-0277.2010.01381.x individuals who become married (Bachman et al., 1997a,b; Chilcoat and Breslau, 1996; Curran et al., 1998; Hajema and Knibbe, 1998; Hanna et al., 1993; Harford et al., 1994; Power and Estaugh, 1990; Temple et al., 1991) or engaged to be married (see Bachman et al., 1997a; Miller-Tutzauer et al., 1991), with the reverse observed of never-married individuals, whose drinking often continues or even increases. Given that marital discord is high among heavy and problem users (for review, see Marshal, 2003), it is not surprising that when they do marry, heavy and problem users are more likely to divorce (Caces et al., 1999; Caetano and Clark, 1998; Collins et al., 2007). Becoming unmarried is also associated with increased drinking (Bachman et al., 1997b; Chilcoat and Breslau, 1996; Hajema and Knibbe, 1998; Magura and Shapiro, 1988; Power and Estaugh, 1990; Power et al., 1999; Temple et al., 1991) and this is especially true of the recently separated (but see Wilsnack et al., 1991).

To date, relatively little is known regarding the impact of alcohol involvement on timing of marital transitions across development (see Leonard and Eiden, 2007). Several studies document the associations between adolescent substance use and early marriage or cohabitation (Chassin et al., 1992; Martino et al., 2004; Newcomb and Bentler, 1985, 1987; Power and Estaugh, 1990; Yamaguchi and Kandel, 1985), but not all are consistent with respect to drinking as opposed to smoking or illicit drug use (e.g., Martino et al., 2004). A few studies report on marital onset past the early- to mid-20s, and still fewer use methods taking into account that individuals who have not yet married (or divorced), may do so in the future. 
Among notable exceptions, $\mathrm{Fu}$ and Goldman (1996) examined marital onset as a function of a range of health behaviors in the National Longitudinal Survey of Youth (NLSY), a prospective cohort of youth initially assessed at ages 14 to 21 . Results of survival analyses indicated significant delays in first marriage associated with heavy drinking observed over a 12-year period through the early 30s. Compared to abstainers and light drinkers, heavy drinking women experienced approximately $40 \%$ lower rates of marriage. A similar pattern was found for heavy drinking men, with marriage rates ranging between 34 and 37\% lower, compared to controls. In a subsequent report on the same sample, Fu and Goldman (2000) found few significant effects of alcohol consumption on timing of divorce examined across a 14-year period.

Forthofer and colleagues (1996) also used survival analysis to examine associations between history of psychiatric disorder and marital onset. In a sample of 15- to 54-year-olds drawn from the National Comorbidity Study (NCS; Kessler et al., 1994), alcohol dependence (AD) was unrelated to early marriage (defined as marriage prior to age 19), "on-time" marriage (between ages 19 and 24), or later marriage (after age 24). However, a greater percentage of individuals with substance use disorders, including AD, were considered "off time" in either direction, relative to those with affective or conduct disorders. Given that later marriage was defined as marriage occurring after age 24 , delays associated with a later cutoff, for example, age 30 or 35 , remain unknown. Forthofer and colleagues (1996) did not examine risks for divorce, but a second report on the same sample found AD to be a moderate predictor of marital duration, with much stronger effects for women than men (Kessler et al., 1998).

In the present study, we examine the relationship between lifetime history of $\mathrm{AD}$ and both marital onset and survival in an adult cohort of Australian twins spanning a wide range of ages, from 28 to 92, born mostly between 1940 and 1964 . We include important control variables to ensure specificity of observed $\mathrm{AD}$ effects, ranging from sociodemographic characteristics, history of psychopathology, to family and childhood risks. Among sociodemographic characteristics are educational attainment, a strong predictor of marital delay (Moore and Waite, 1981), and age at childbearing. Age at childbearing is included given well-documented associations with early marriage, but also potential protective effects of children against separation (Cherlin, 1977; Waite and Lillard, 1991). We further extend previous work by examining heritable sources of observed AD-marital transition covariation. Genetic variation in AD is considerable for both men and women (Heath et al., 1997; Kendler et al., 1994; McGue, 1994), with genetic variation in marital status also reported (Jockin et al., 1996; Johnson et al., 2004; Mcgue and Lykken, 1992; Trumbetta et al., 2007). Although heritable covariation has been suggested (Osler et al., 2008; Prescott and Kendler, 2001), whether there is genetic overlap between $\mathrm{AD}$ and timing of marital transitions is currently unknown.

\section{MATERIALS AND METHODS}

\section{Participants}

Respondents were twins born between 1893 and 1964, with approximately $80 \%$ of the sample born between 1940 and 1964, drawn from a broadly representative Australian volunteer twin panel maintained by the Australian National Health and Medical Research Council (NHMRC). Twins are of primarily European decent reflecting the predominantly Caucasian Australian population from which the cohort was ascertained. While well-educated individuals are overrepresented, any impact of differential participation rates as a function of educational attainment appears minimal (Heath et al., 1997, 2001), as does potential bias with respect to drinking behavior (Jardine and Martin, 1984).

Twins were recruited as adults and first surveyed by mailed questionnaire over the period 1980 to 1981 (Heath et al., 1997). During 1988-1989, pairs for whom both twins returned the 1980-1981 questionnaire were asked to complete a follow-up questionnaire replicating most of the original items, with additional assessment of female reproductive health. In 1992, all twins from the 1988-1989 sample (along with a small sample of twins from an earlier laboratory study; Martin et al., 1985a,b) were asked to complete a structured diagnostic interview. Twins were selected for analysis if they had data on lifetime DSM-III-R AD symptoms assessed during the 1992 interview and variables used to code marital onset, which were included in the 1988-1989 questionnaire, but omitted from interview. Of 5,879 individual twins completing 1988-1989 questionnaire and interview, $5,420(92 \%)$ had data on both AD and marital onset, including 3,575 female and 1,845 male respondents. This includes data from 2,338 monozygotic (MZ) and dizygotic (DZ) twin pairs $\left(n_{\text {female } \mathrm{Mz}}=828\right.$, $n$ male $\mathrm{MZ}=345, n_{\text {female } \mathrm{DZ}}=461, n_{\text {male } \mathrm{DZ}}=184, n_{\text {opposite-sex DZ }}$ $=520)$ and 744 nonpair twins. Age at interview ranged from 28 to $92[$ Mean $(\mathrm{SD})=44.41(12.25)]$.

\section{Measures}

Twins completed a 20-page self-report questionnaire assessing health behavior, including alcohol use and smoking histories, and a telephone adaptation of the Semi-Structured Assessment of the Genetics of Alcoholism (SSAGA; Bucholz et al., 1994; Hesselbrock et al., 1999). The SSAGA was developed for the Collaborative Study on the Genetics of Alcoholism (COGA) to assess physical, psychological, and social manifestations of alcohol abuse or dependence and related psychiatric disorders in adults and is based on previously validated research interviews (e.g., DIS, CIDI, HELPER, SAM, SADS, and SCID). Trained interviewers, who were supervised by a project coordinator and clinical psychologist, administered all interviews. Interviews were tape-recorded and a random sampling of tapes was reviewed for quality control and coding inconsistencies. Informed consent was obtained from all participants prior to their participation using procedures approved by the institutional review boards at both Washington University School of Medicine and Queensland Institute of Medical Research.

Measures were drawn from interview assessments unless otherwise indicated. A summary of individual measures follows, with descriptive statistics presented in Table 1 by cohort and respondent sex. Where available, age of onset is also shown.

\section{Marital Onset}

Marital onset was computed from date of first marriage or when the respondent began living in a de facto (common law) partnership. Respondents were asked to provide dates of up to three marriages or partnerships in the 1988-1989 questionnaire only. Marital history was assessed only briefly during interview, with respondents who were married or currently living with a partner as though married asked to report years of marriage to current partner, regardless of 
Table 1. Descriptive Statistics, by Respondent Gender

\begin{tabular}{|c|c|c|}
\hline & Women $(n=3,575)$ & $\operatorname{Men}(n=1,845)$ \\
\hline Ever married & $3,160(88)$ & $1,532(83)$ \\
\hline Age at first marriage, mean (SD) & $23.21(3.94)$ & $25.53(4.23)$ \\
\hline Ever separated/divorced from first marital partner, $n(\%)$ & $437(14)$ & $187(12)^{\text {NS }}$ \\
\hline Age at first separation, mean (SD) & $32.55(8.49)$ & $33.66(9.02)^{\mathrm{NS}}$ \\
\hline Time (years) to separation, mean (SD) & $10.63(8.07)$ & $9.15(8.08)^{\mathrm{NS}}$ \\
\hline $\mathrm{AD}, n(\%)$ & $204(6)$ & $430(23)$ \\
\hline Age of onset, mean (SD) & $27.52(8.82)$ & $24.35(7.72)$ \\
\hline \multicolumn{3}{|l|}{ Control variables } \\
\hline Biologic children, $n(\%)$ & $2,729(77)$ & $1,243(67)$ \\
\hline Age at first childbirth, mean (SD) & $25.40(4.04)$ & $28.00(4.26)$ \\
\hline \multicolumn{3}{|l|}{ Educational attainment } \\
\hline Early school leaver, $n(\%)$ & $1,221(34)$ & $292(16)$ \\
\hline High school, no tertiary education, $n(\%)$ & $1,311(37)$ & $699(38)^{\mathrm{NS}}$ \\
\hline \multicolumn{3}{|l|}{ Religiosity } \\
\hline Religious affiliation, $n(\%)$ & $2,932(87)$ & $1,376(80)$ \\
\hline Weekly church attendance, $n(\%)$ & $849(25)$ & $372(22)$ \\
\hline Regular smoking, $n(\%)$ & $1,473(41)$ & $909(49)$ \\
\hline $\mathrm{CD}, n(\%)$ & $81(2)$ & $305(17)$ \\
\hline MDD, $n(\%)$ & $778(22)$ & $288(16)$ \\
\hline Suicide attempt, $n(\%)$ & $109(3)$ & $37(2)$ \\
\hline Panic attack, $n(\%)$ & $145(4)$ & $41(2)^{a}$ \\
\hline Maternal alcoholism, $n(\%)$ & $132(4)$ & $54(3)^{N S}$ \\
\hline Paternal alcoholism, $n(\%)$ & $602(17)$ & $299(17)^{N S}$ \\
\hline CSA, $n(\%)$ & $198(6)$ & 47 (3) \\
\hline
\end{tabular}

${ }^{\mathrm{a}} p=0.02$.

${ }^{N S}$ Gender difference not significant at $p=0.05$; AD, alcohol dependence; CD, childhood conduct disorder; MDD, major depressive disorder; CSA, childhood sexual abuse.

any prior separation. Years of marriage were not assessed of separated or divorced and widowed respondents not currently remarried and/or living with a partner.

\section{Marital Survival}

Age at separation from first marital partner was coded from the year of first marriage or de factor partnership ended for respondents reporting history of separation or divorce. As with marital onset, dates of separation from first and subsequent marriages or partnerships were assessed in the 1988-1989 questionnaire only.

\section{Alcohol Use Disorder}

Lifetime history of AD was coded according to DSM-III-R criteria, with age of onset directly assessed (age at first 12-month clustering of three or more AD symptoms). The SSAGA administered predates publication of DSM-IV criteria. Although an approximate algorithm for DSM-IV AD without clustering criteria has been developed (see Heath et al., 2001), data on age of onset of DSM-IV $\mathrm{AD}$ are incomplete as a consequence of DSM-III-R assessment. DSM-III-R was instead analyzed given the importance for the present analysis of ensuring that onset of $\mathrm{AD}$ precede first marriage and subsequent separation.

\section{Control Variables}

Important correlates of $\mathrm{AD}$ were selected as control variables based on review of the literature and availability in the current sample, including, for comparability, control variables examined in previous analyses of AD and reproductive timing (Waldron et al., 2008).

Sociodemographic Characteristics. In addition to birth year, coded in 5-year intervals, educational attainment and religiosity were included among sociodemographic control variables, all of which were drawn from the 1988-1989 questionnaire. Dummy variables for leaving high school prior to grade 12 and completing high school (e.g., earning the equivalent of a high school diploma) were computed with any tertiary education comprising the reference group. Respondents reporting any versus no religion were coded positive for religious affiliation. Weekly or more church attendance was coded from respondent report of frequency of church attendance using a scale ranging from $1=$ "more than once a week" to $5=$ "rarely," with 2 = "once a week."

Reproductive History. Age at first childbirth was computed by subtracting respondent's date of birth from the date of birth of his or her first-born biologic child. In adjusted models predicting marital survival, age at childbirth was dummy-coded from time-varying person-year data as age at first, second, and third childbirth, with respondents reporting no children comprising the reference group. Respondents were asked to provide dates of birth of up to 10 biologic children in the 1988-1989 questionnaire only.

Smoking History. History of regular smoking was assessed only in the 1988-1989 questionnaire. Respondents who self-described as "ex-" or "current smoker"(s) were coded positive for regular smoking. Age of onset of regular smoking was not assessed.

History of Psychopathology. Childhood conduct disorder (CD), lifetime history of major depressive disorder (MDD), and suicide attempt and panic attack histories were included among psychiatric control variables, each assessed as part of the SSAGA. Relaxed criteria were used to diagnose $\mathrm{CD}$, defined as three or more DSM-IV CD symptoms each with onset before age 18. Likewise, the broader construct of panic attack, rather than panic disorder, was used. DSM-IV criteria were applied to DSM-III-R assessment of MDD and panic attack. History of attempted suicide was also assessed.

Family and childhood risks. Maternal and paternal alcohol problems were coded from respondent report of biologic parent history of alcohol-related problems with health, family, job, or police, or other problems. Childhood sexual abuse 
(CSA) was defined as unwanted or forced sexual activity prior to age 18 .

\section{Zygosity}

Zygosity was diagnosed based on twins' responses to standard questions regarding similarity and the degree to which others confused them (Nichols and Bilbro, 1966). Diagnoses derived from extensive blood sampling have been shown to demonstrate $95 \%$ agreement with similar questionnaire-based zygosity determination (Martin, 1975; Ooki et al., 1990).

\section{Analytic Strategy}

The present study analyzes data from individual twins to examine phenotypic associations between marital timing and AD and among ever-married individuals, time to separation and AD. Pair-level data were analyzed to examine potential heritable sources of covariation. Because not all respondents had aged through periods of highest likelihood of marriage or separation, time-to-event data were analyzed using survival analysis. Analyses were conducted separately for women and men given well-documented sex differences in the prevalence of $\mathrm{AD}$ and sex differences in marital onset, with women marrying at earlier ages on average than men (ABS, 2009; U.S. Census Bureau, 2010).

In preliminary analyses, cumulative failure curves were estimated using the Kaplan-Meier survivor function (Kaplan and Meier, 1958), with log-rank tests to identify significant differences in equality of survivor functions by sex. We also tested for zygosity differences that might identify limitations to the generalizability of twin data. Because MZ twinning occurs at random, MZ twins will represent a near-random sample of genotypes in the general population. In contrast, DZ twining shows weak associations with factors including maternal age and socioeconomic status (Bulmer, 1970).

To examine marital onset as a function of AD history, without and with adjustment for control variables, Cox proportional hazards regression (Cox, 1972) was used. AD was modeled as a time-varying predictor to ensure onset before or at the same time as first marriage. This was achieved using person-year data, with each line of data representing a single year of life for every respondent. For respondents reporting history of $\mathrm{AD}, \mathrm{AD}$ was coded as absent in each year up to the age they first met criteria and present from that year onward. Among ever-married individuals, AD was modeled as a time-varying predictor of age at separation from first marital partner, with respondents entering the analysis (or risk set) at marital onset and widow/ers right-censored upon spousal death. Age at childbirth was also examined as a time-varying predictor in adjusted models, with respondents reporting biologic children coded as having none in each year up to childbirth and having one or more from year of childbirth onward. In analyses of marital onset, age at first childbirth was included to control for premarital childbearing. Age at first, second, and third childbirth were included to control for number of biologic children born prior to or in the same year as marital separation. The Efron approximation (Efron, 1977) was used for survival ties.

Given the wide age range of respondents, we also tested for age by $\mathrm{AD}$ interactions. For these analyses, birth year was re-coded in 5year increments over the range of 1945 to 1959 and birth years prior to 1945 were collapsed into a single dummy variable, with the most recent cohort born between 1960 and 1964 comprising the reference group. Post hoc tests were conducted to examine whether any of the birth-year dummy variables could be equated followed by tests for interactions with AD.

Analyses of genetic influences contributing to observed associations between $\mathrm{AD}$ and marital timing and survival were conducted using data from complete MZ and DZ twin pairs. The following variables were modeled as predictors in genetically informed Cox analyses: respondent $\mathrm{AD}$, zygosity, cotwin $\mathrm{AD}$, the interaction between zygosity and cotwin AD (a test of genetic effects), cotwin sex, and the interaction of zygosity, cotwin AD, and cotwin sex (a test of sex differences in genetic effects). Respondent history of AD was modeled as a time-varying predictor, with cotwin AD included as time-invariant. To examine the differential effects of early versus later onset, cotwin $\mathrm{AD}$ was also dummy-coded as occurring before or on versus after the median age of onset for women or men (ages 24 and 21, respectively), with nonalcoholic cotwins comprising the reference group. To examine the overall genetic contribution to covariation, without regard to univariate heritability, respondent AD was excluded from genetically informed models of marital timing and survival in separate analyses.

Results from Cox models are presented as hazard ratios (HRs). In Cox regression, the dependent variable is called the hazard, which describes event occurrence over time or the rate of event occurrence. A hazard rate is a conditional instantaneous event rate, calculated as a function of time. For dichotomous predictors, HRs represent a ratio of hazard rates for two groups; that is, the ratio of rates at which events are occurring in one group relative to a reference group. HRs $>1.0$ indicate a higher rate of event occurrence; thus, in the context of this study, earlier marriage compared to the reference group. HRs $<1.0$ indicate a lower rate, suggesting later or delayed marriage compared to the reference group. HRs $=1.0$ indicate no difference in rates or risk related to onset of marriage. The same is true for marital separation, i.e., HRs greater and $<1.0$ indicate higher and lower rates of separation, respectively.

All survival analyses were conducted using STATA version 8.2 (StataCorp, 2005), with the Huber-White robust variance estimator used to compute standard errors and confidence intervals adjusted for nonindependence (i.e., the correlated nature) of data on twin pairs. An important assumption of Cox regression is that of proportional hazards. Violations of proportional hazards, such as might be the case if $\mathrm{AD}$ effects on marital onset or survival differ for earlier versus later age periods, were examined using the Grambsch and Therneau test of Schoenfeld residuals (Grambsch and Therneau, 1994), which involves testing for a nonzero slope in a regression of scaled Schoenfeld residuals on functions of time for each predictor variable. Following Cleves and colleagues (2004), interactions between age or risk period and predictor variables were modeled to correct observed proportional hazards violations. Where there was no violation in proportional hazards, risk periods were collapsed.

\section{RESULTS}

\section{Preliminary Analyses}

As shown in Table 1, more women than men reported having ever-married. Results of log-rank tests indicate significant sex differences in the cumulative probability of first marriage, with women marrying earlier on average than men. Among ever-married individuals, an approximately equal proportion of women and men separated from their first marital partner. Sex differences in the cumulative probability of separation were nonsignificant. Consistent with previous reports, rates of $\mathrm{AD}$ were higher for men than women, with onset of $\mathrm{AD}$ occurring earlier on average for men. For control variables, sex differences were significant at $p<0.01$ unless otherwise noted.

Tests for zygosity differences in marital onset, marital survival, and AD provide support for generalizability of twin data to singleton populations. Nonsignificant differences by zygosity were observed in the cumulative probability of first marriage (women: $\chi_{1}^{2}=2.38, p=0.12$; men: $\chi_{1}^{2}=0.12$, 
Table 2. Hazard Ratios (and 95\% Cls) From Cox Proportional Hazards Models of Marital Onset

\begin{tabular}{|c|c|c|c|c|}
\hline \multirow[b]{2}{*}{ Predictor (risk period) ${ }^{a}$} & \multicolumn{2}{|c|}{ Women } & \multicolumn{2}{|c|}{ Men } \\
\hline & Unadjusted & Adjusted & Unadjusted & Adjusted \\
\hline $\mathrm{AD}(<30)$ & $0.77(0.63-0.96)$ & $0.69(0.52-0.92)$ & $0.96(0.81-1.14)$ & $0.86(0.71-1.05)$ \\
\hline$A D(\geq 30)$ & $\perp$ & $1.74(0.93-3.28)$ & $0.64(0.43-0.95)$ & 1 \\
\hline Control variables & & & & \\
\hline Birth year $(<20)$ & & $1.13(1.07-1.18)$ & & $1.01(0.98-1.04)$ \\
\hline Birth year (20-25) & & $1.02(1.00-1.04)$ & & $\perp$ \\
\hline Birth year $(\geq 25)$ & & $0.93(0.91-0.96)$ & & $0.92(0.88-0.94)$ \\
\hline Age at first childbirth $(<20)$ & & $15.95(10.92-23.29)$ & & 41.71 (8.83-196.93) \\
\hline Age at first childbirth (20-24) & & $4.12(3.21-5.28)$ & & $6.78(4.29-10.71)$ \\
\hline Age at first childbirth $(\geq 25)$ & & $3.03(2.11-4.35)$ & & $4.46(2.95-6.73)$ \\
\hline HS dropout $(<20)$ & & $9.02(6.00-13.57)$ & & $1.08(0.09-1.30)$ \\
\hline HS dropout (20-24) & & $1.74(1.51-2.01)$ & & \\
\hline HS dropout (25-29) & & $1.05(0.83-1.33)$ & & \\
\hline HS dropout $(\geq 30)$ & & $3.29(1.65-6.57)$ & & \\
\hline HS degree $(<20)$ & & $3.65(2.46-5.44)$ & & $1.17(1.03-1.34)$ \\
\hline HS degree (20-24) & & $1.27(1.11-1.44)$ & & \\
\hline HS degree (25-35) & & $1.03(0.83-1.27)$ & & \\
\hline HS degree $(\geq 35)$ & & $1.85(1.30-2.66)$ & & $\perp$ \\
\hline Religious affiliation & & $1.10(0.96-1.26)$ & & $1.04(0.88-1.23)$ \\
\hline Weekly church attendance & & $0.86(0.78-0.95)$ & & $0.97(0.84-1.12)$ \\
\hline Regular smoking & & $0.94(0.86-1.02)$ & & $1.27(1.12-1.43)$ \\
\hline$C D$ & & $0.98(0.66-1.45)$ & & $1.18(0.99-1.39)$ \\
\hline $\operatorname{MDD}(<25)$ & & $1.16(1.04-1.30)$ & & 1.01 (0.86-1.19) \\
\hline MDD $(\geq 25)$ & & $0.92(0.76-1.13)$ & & $\perp$ \\
\hline Suicide attempt $(<25)$ & & $1.04(0.78-1.40)$ & & $0.82(0.34-1.96)$ \\
\hline Suicide attempt $(\geq 25)$ & & $1.61(0.95-2.71)$ & & $0.22(0.08-0.60)$ \\
\hline Panic attack & & $1.09(0.88-1.35)$ & & $1.05(0.67-1.65)$ \\
\hline Maternal alcoholism & & $1.02(0.81-1.30)$ & & $1.62(1.22-2.15)$ \\
\hline Paternal alcoholism & & $0.96(0.85-1.09)$ & & $1.00(0.85-1.18)$ \\
\hline CSA & & $1.00(0.83-1.22)$ & & $0.76(0.53-1.09)$ \\
\hline
\end{tabular}

${ }^{\mathrm{a}}$ Risk period in years of age.

Bold = significant effects. AD, alcohol dependence; HS, high school; CD, childhood conduct disorder; MDD, major depressive disorder; CSA, childhood sexual abuse.

$p=0.73)$ and separation among ever-married individuals (women: $\chi_{1}^{2}=1.17, p=0.28$; men: $\chi_{1}^{2}=2.98, p=0.08$ ). Zygosity was also unrelated to $\mathrm{AD}$ (women: $\chi_{1}^{2}=1.77$, $p=0.18$; men: $\chi_{1}^{2}=3.40, p=0.07$ ).

\section{Cox Analyses of Marital Timing and Survival}

Hazard ratios and 95\% CIs from models unadjusted and adjusted for sociodemographic, reproductive, psychiatric, and family, and childhood risks are presented in Tables 2 and 3 for marital onset and survival, respectively. Not shown are results from models testing for birth year by AD interactions, which were nonsignificant in all models examined.

Marital Onset. For both women and men, there was a moderate association between AD and delayed marital onset. For women, onset of AD was associated with $23 \%$ decreased likelihood of first marriage, with no significant age interaction. In adjusted models, $31 \%$ decreased likelihood of first marriage was observed, but through age 29. For men, onset of AD was associated with marital delay only after age 29, with $36 \%$ decreased likelihood of first marriage. However, in adjusted models, across age, effects of AD for men were nonsignificant.

Several control variables were also robust predictors of marital onset. Through age 19, having a child was associated with nearly 16 times the likelihood of first marriage for women and over 40 times for men. After age 19, risks reduce but remain high for both women and men. Dropping out of high school predicted early marriage for women only. Effects were especially pronounced through age 19, with dropping out associated with 9 times the likelihood of first marriage. Completing high school without continued schooling predicted early marriage for both women and men, although the relationship was considerably weaker for men. For women, weekly church attendance predicted a slight delay in marital onset, with little to no effect observed for men. Among psychiatric risks, MDD was associated with $16 \%$ increased likelihood of first marriage for women through age 24. For men, past suicide attempt was associated with $88 \%$ decreased likelihood of first marriage through age 24 . Of significant family and childhood risks, maternal alcoholism predicted early marriage for men, with $62 \%$ increased likelihood. Regular smoking was associated with earlier marriage for men only.

Marital Survival. For both women and men, there was a strong association between AD and early separation. Likelihood of marital separation among alcoholic women was over two times that of nonalcoholics, with no significant age interaction, but this effect disappeared in adjusted models. For men, onset of AD was also associated with over two 
Table 3. Hazard Ratios (and 95\% Cls) From Cox Proportional Hazards Models of Marital Survival

\begin{tabular}{|c|c|c|c|c|}
\hline \multirow[b]{2}{*}{ Predictor (risk period) ${ }^{a}$} & \multicolumn{2}{|c|}{ Women } & \multicolumn{2}{|c|}{ Men } \\
\hline & Unadjusted & Adjusted & Unadjusted & Adjusted \\
\hline$A D$ & $2.42(1.54-3.82)$ & $0.95(0.55-1.64)$ & $2.45(1.76-3.40)$ & $1.84(1.22-2.77)$ \\
\hline \multicolumn{5}{|l|}{ Control variables } \\
\hline Birth year & & $1.16(1.10-1.22)$ & & $1.10(1.02-1.20)$ \\
\hline 1 child $(<25)$ & & $3.10(1.79-5.37)$ & & $1.08(0.67-1.75)$ \\
\hline 1 child $(\geq 25)$ & & $0.58(0.39-0.88)$ & & $\perp$ \\
\hline 2 children & & $0.61(0.44-0.85)$ & & $1.03(0.63-1.69)$ \\
\hline $3+$ children & & $0.57(0.40-0.80)$ & & $0.64(0.35-1.18)$ \\
\hline HS dropout $(<35)$ & & $1.09(0.82-1.46)$ & & $1.82(1.05-3.16)$ \\
\hline HS dropout $(\geq 35)$ & & $\perp$ & & $0.92(0.42-2.00)$ \\
\hline HS degree & & $1.12(0.85-1.46)$ & & $1.26(0.87-1.83)$ \\
\hline Religious affiliation & & $0.66(0.50-0.89)$ & & $0.49(0.33-0.73)$ \\
\hline Weekly church attendance $(<25)$ & & $0.52(0.39-0.71)$ & & $2.01(0.74-5.43)$ \\
\hline Weekly church attendance $(\geq 25)$ & & $\perp$ & & $0.51(0.27-0.95)$ \\
\hline Regular smoking & & $1.49(1.20-1.85)$ & & $1.39(0.96-2.01)$ \\
\hline$C D(<25)$ & & $1.19(0.65-2.20)$ & & $2.41(0.98-5.89)$ \\
\hline$C D(\geq 25)$ & & $\perp$ & & $0.67(0.39-1.15)$ \\
\hline $\operatorname{MDD}(<25)$ & & $1.02(0.57-1.85)$ & & $3.13(2.20-4.46)$ \\
\hline $\operatorname{MDD}(\geq 25)$ & & $2.29(1.81-2.91)$ & & $\perp$ \\
\hline Suicide attempt & & $1.78(1.12-2.84)$ & & $3.78\left(\frac{1}{1.81}-7.90\right)$ \\
\hline Panic attack $(<35)$ & & $0.78(0.48-1.27)$ & & $2.49(0.84-7.37)$ \\
\hline Panic attack $(\geq 35)$ & & $1+$ & & $\sim 0$ \\
\hline Maternal alcoholism & & $1.22(0.72-2.04)$ & & $0.71(0.26-1.93)$ \\
\hline Paternal alcoholism & & $1.03(0.79-1.35)$ & & $1.37(0.89-2.13)$ \\
\hline CSA & & $1.21(0.79-1.87)$ & & $0.77(0.25-2.34)$ \\
\hline
\end{tabular}

${ }^{\text {a }}$ Risk period in years of age.

Bold = significant effects. AD, alcohol dependence; HS, high school; CD, childhood conduct disorder; MDD, major depressive disorder; CSA, childhood sexual abuse.

times the likelihood of separation. Significant albeit somewhat reduced effects were observed in adjusted models, with $84 \%$ increased likelihood of marital separation.

Among control variables, age at first childbirth was strongly predictive of marital survival, but for women only. Through age 24, having a single child was associated with over 3 times the likelihood of separation, compared to women without children. Having a single child was protective against separation from age 25 onwards as was having two or three or more children. While educational attainment was unrelated to marital survival for women, high school dropout was associated with a nearly 2 times increased likelihood of separation for men through age 34 . Religious affiliation and weekly church attendance strongly predicted delayed separation for both women and men. History of MDD was associated with over two times the likelihood of separation for women after age 24 and for men, across age, over three times. Past suicide attempt was also predictive of early separation for both women and men - for women, a $78 \%$ increased likelihood was observed and for men, nearly four times. Regular smoking was associated with earlier separation for women and nonsignificant but trend-level effects were observed for men.

\section{Analyses of Genetic Covariation}

Hazard ratios and 95\% CIs from Cox proportional hazards models of genetic covariation between AD and marital onset and survival are shown in Tables 4 and 5, respectively.
Not shown are results from models that exclude respondent $\mathrm{AD}$, which were nearly identical to those reported below.

Marital Onset. For both women and men, genetic effects were nonsignificant in models of marital timing where cotwin AD was examined without regard to onset (see Model 1). Neither the interaction of zygosity and cotwin AD nor the interaction of zygosity, cotwin AD and cotwin sex were significant, suggesting the absence of omnibus genetic and sexdependent genetic effects, respectively. In models with cotwin AD coded as occurring on or before versus after the median age of onset (Model 2), genetic effects were observed, but for women only. For women, the interaction of zygosity and cotwin $\mathrm{AD}$ with onset before age 25 predicted delayed marital onset, with the interaction of zygosity and cotwin $\mathrm{AD}$ and cotwin sex nonsignificant.

Marital Survival. In models of genetic covariation between marital survival and AD, sex-dependent genetic effects were observed for both women and men. For women, the interaction of zygosity, cotwin $\mathrm{AD}$, and cotwin sex predicted early separation (Model 1), with female like-sex pairs showing earlier separation than opposite-sex pairs. For men, the interaction of zygosity and cotwin $\mathrm{AD}$ with onset after age 21 predicted early separation (Model 2). The addition of cotwin sex to the interaction indicates significant sex differences in the direction of men from like-sex pairs showing dramatically earlier separation those from opposite-sex pairs. 
Table 4. Hazard Ratios (and 95\% Cls) From Cox Proportional Hazards Models of Genetic Covariation Between AD and Marital Onset

\begin{tabular}{|c|c|c|}
\hline Predictors (risk period) ${ }^{a}$ & Women & Men \\
\hline \multicolumn{3}{|l|}{ Model 1} \\
\hline Respondent AD (<30) & $0.80(0.64-1.00)$ & $0.99(0.82-1.19)$ \\
\hline Respondent AD $(\geq 30)$ & $\perp$ & $0.64(0.42-0.97)$ \\
\hline Zygosity & $1.07(0.87-1.32)$ & $1.25(0.88-1.78)$ \\
\hline Cotwin $A D$ & $1.16(0.66-2.02)$ & $1.55(0.81-2.95)$ \\
\hline Zygosity cotwin $A D$ & $0.41(0.07-2.51)$ & $0.18(0.02-2.06)$ \\
\hline Cotwin sex & $1.12(0.98-1.28)$ & $0.93(0.78-1.10)$ \\
\hline Zygosity cotwin AD cotwin sex & $1.36(0.70-2.64)$ & $1.95(0.72-5.32)$ \\
\hline \multicolumn{3}{|l|}{ Model 2} \\
\hline Respondent AD $(<30)$ & $0.83(0.67-1.03)$ & $0.99(0.82-1.19)$ \\
\hline Respondent AD $(\geq 30)$ & $\perp$ & $0.64(0.42-0.97)$ \\
\hline Zygosity & $1.08(0.88-1.33)$ & $1.18(0.83-1.68)$ \\
\hline Cotwin early $A D$ & $2.62(1.00-6.86)$ & $1.45(0.58-3.64)$ \\
\hline Cotwin later AD & $0.85(0.41-1.75)$ & $1.05(0.45-2.47)$ \\
\hline Zygosity cotwin early AD & $0.04(0.002-0.82)$ & $0.35(0.01-10.54)$ \\
\hline Zygosity cotwin later $A D$ & $0.82(0.07-9.06)$ & $0.62(0.02-17.66)$ \\
\hline Cotwin sex & $1.11(0.97-1.27)$ & $0.95(0.80-1.13)$ \\
\hline Zygosity cotwin early AD cotwin sex & $2.25(0.81-6.24)$ & $1.48(0.37-5.86)$ \\
\hline Zygosity cotwin later AD cotwin sex & $1.29(0.52-3.19)$ & $1.25(0.31-5.00)$ \\
\hline
\end{tabular}

${ }^{a}$ Risk period in years of age.

Bold = significant effects. AD, alcohol dependence.

Table 5. Hazard Ratios (and 95\% Cls) From Cox Proportional Hazards Models of Genetic Covariation Between AD and Marital Survival

\begin{tabular}{|c|c|c|}
\hline Predictors (risk period) ${ }^{\mathrm{a}}$ & Women & Men \\
\hline \multicolumn{3}{|l|}{ Model 1} \\
\hline Respondent AD & $2.22(1.36-3.63)$ & $2.48(1.73-3.54)$ \\
\hline Zygosity & $0.89(0.54-1.45)$ & $1.04(0.35-3.08)$ \\
\hline Cotwin AD & $0.57(0.13-2.43)$ & $1.21(0.24-6.14)$ \\
\hline Zygosity cotwin AD & $2.60(0.02-381.36)$ & $14.57(0.05-4625.88)$ \\
\hline Cotwin sex $(<35)$ & $1.56(1.01-2.41)$ & $0.70(0.03-2.56)$ \\
\hline Cotwin sex $(\geq 35)$ & $0.85(0.51-1.43)$ & $\perp$ \\
\hline Zygosity cotwin AD cotwin sex & $1.40(1.01-2.41)$ & $0.70(\stackrel{\perp}{0.41-1.19)}$ \\
\hline \multicolumn{3}{|l|}{ Model 2} \\
\hline Respondent AD & $2.19(1.33-3.61)$ & $2.44(1.71-3.49)$ \\
\hline Zygosity & $0.90(0.56-1.48)$ & $1.03(0.36-2.98)$ \\
\hline Cotwin early $A D$ & $0.91(0.08-9.45)$ & $4.35(0.62-30.65)$ \\
\hline Cotwin later AD & $0.46(0.07-3.11)$ & $0.09(0.002-4.73)$ \\
\hline Zygosity cotwin early AD & $0.31(0.0001-836.06)$ & $0.004(\sim 0-76.71)$ \\
\hline Zygosity cotwin later $A D$ & $11.58(0.02-7592.85)$ & $250,566(1.11$ to $>100)$ \\
\hline Cotwin sex $(<35)$ & $1.58(1.02-2.42)$ & $0.71(0.42-1.18)$ \\
\hline Cotwin sex $(\geq 35)$ & $0.87(0.52-1.46)$ & $\perp$ \\
\hline Zygosity cotwin early AD cotwin sex & $3.81(0.19-76.03)$ & $8.80(0.11-704.20)$ \\
\hline Zygosity cotwin later AD cotwin sex & $0.67(0.06-7.73)$ & $0.01(0.0001-0.55)$ \\
\hline
\end{tabular}

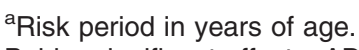

Bold = significant effects. AD, alcohol dependence.

\section{DISCUSSION}

Although associations between drinking behavior and marital status are well documented, as are changes in drinking as a function of entry into (and out of) marriage, timing of marital transitions as a function of alcohol use or disorder has received only limited empirical attention. In this study, we examined the relationship between lifetime history of AD and onset of first marriage, and among ever-married individuals, survival of first marriage. We used survival analysis to gauge overall likelihood of marriage and separation, as well as timing of these events, including control variables with well-documented association with AD. Capitalizing on the availability of genetically informed twin data, we also examined potential heritable sources of covariation contributing to observed associations.

Consistent with $\mathrm{Fu}$ and Goldman (1996), a pattern of delayed marital onset was observed among alcoholic compared to nonalcoholic individuals. For women, AD was associated with reduced likelihood of marriage regardless of adjustment for important sociodemographic, reproductive, psychiatric, and family and childhood risks; a significant age interaction was found in adjusted models, with delays observed through age 29. For men, marital delays associated with $\mathrm{AD}$ were observed in unadjusted models, but only after age 29. Regarding marital survival, consistent with Kessler 
and colleagues (1998), among ever-married women and men, a pattern of early separation was found without age interaction. In unadjusted models, likelihood of separation was nearly double for alcoholic compared to alcoholic individuals. However, for ever-married women, the association between $\mathrm{AD}$ and marital survival reduced to nonsignificance in adjusted models.

Together, results suggest AD may work to delay marriage for women during earlier risk periods, i.e., their 20s, when most women in this cohort married. Although men on average married only a year or 2 later, marital delay associated with $\mathrm{AD}$ appears more pronounced for men starting around age 30 . Such differences may be related to the relative rarity of $\mathrm{AD}$ among women in this cohort, with $\mathrm{AD}$ perhaps representing a more severe phenotype than for men, and this would be especially true of early-onset $\mathrm{AD}$, i.e., $\mathrm{AD}$ preceding marital onset in the 20s. In contrast, effects of AD on marital survival do not appear to differ by risk period, although reduced statistical power associated with low prevalence outcomes, such as separation (with 12 to $14 \%$ prevalence in this cohort), may be a factor.

As noted, AD remained predictive of marital onset for women and marital survival for men in the presence of highly correlated sociodemographic, reproductive, psychiatric, and family and childhood risks. This includes birth year, a surprising finding given major changes in Australian divorce law easing a number of restrictions, including financial barriers, for obtaining divorce (Donaldson, 2004). In 1959, a system of fault-based divorce allowed dissolution of marriage upon obtaining proof of marital fault, with a single no-fault option available to those who were separated for more than 5 years. Australia moved to an entirely no-fault system in 1975, providing that the marriage was "broken down irretrievably," with spouses having lived separately for at least 12 months.

Two control variables, in particular, were strongly predictive of marital timing - educational attainment and age at first childbirth. Leaving school prior to grade 12 was associated with early marriage for women, as was completing high school without continued schooling, together consistent with the larger literature on educational correlates of early versus later marriage (Moore and Waite, 1981). For men, completing high school was associated with early marriage, with no effect of leaving school prior to grade 12. Educational attainment was also significant in analyses of marital survival, but for men only-leaving school prior to grade 12 was associated with early separation through age 34 , with no effect of high school completion school without continued schooling.

Childbirth was a powerful predictor of marital onset for both women and men, and this was especially true prior to age 20. While effects were strongest during the teen years, childbirth continued to predict early marriage from age 20 onwards. Interestingly, for women, having a single child was associated with increased likelihood of separation through age 24 , but protective against separation from age 25 onwards. Having 2 or 3 or more children was equally protective, consistent with research suggesting reduced risks of marital separation where children are involved (Cherlin, 1977; Waite and Lillard, 1991). For men, having children was unrelated to marital survival.

In a previous report, we documented a strong relationship between $\mathrm{AD}$ and delayed reproduction among women, with a negligible effect observed for men (Waldron et al., 2008). Although timing of marriage and reproduction are highly correlated, $\mathrm{AD}$ was associated with delayed marriage for both sexes. It is possible that onset of marriage and reproduction are more closely linked for alcoholic women than men. Alcoholic women may be less likely to marry, and thus less likely to reproduce, particularly in the present cohort, where early marriage is relatively normative. Of course, reproductive impairments from prolonged or excessive drinking compound such effects (Emanuele et al., 2002), perhaps explaining why AD-related reproductive delays are much stronger than those observed for marriage, at least among women.

Other control variables were also predictive of marital timing, including comorbid psychopathology. For women, MDD was associated with early marriage through age 24 and separation from age 24 onwards. MDD was unrelated to marital onset for men, but strongly predictive of early separation. Attempted suicide was associated with marital delay for men through age 24 , and early separation for both women and men. Owing to limited assessment, we examined the lifetime history of both MDD and attempted suicide and thus are unable to establish direction of effects with regard to marital timing, but also AD. Depression and AD are highly comorbid and disentangling cause from consequence, especially in light of alcohol-involved marriages, merits further examination.

Although other yet unmeasured covariates may be important, there are several possible explanations of observed marital delays, assuming AD contributes uniquely to timing of first marriages. Alcoholic women and men may be less attractive to potential mates, making for less suitable partners; they may also be less likely to commit to conventional relationships, particularly during younger years. There is also the possibility that alcoholic individuals choose to remain single for longer. By remaining single, regardless of reason, risks for AD may increase as a consequence of continued alcohol use in part because of continued participation in alcohol-oriented singles events and/or stress associated with not marrying, including both social and financial.

Partner effects are also likely. In addition to assortative mating (Agrawal et al., 2006; Grant et al., 2007; Labouvie, 1996), there is growing evidence of spousal concordance for drinking over the marriage course (Demers et al., 1999; Leonard and Eiden, 1999; Leonard and Mudar, 2004), with higher rates of marital dissatisfaction observed among spouses discordant for heavy or problem drinking (Homish and Leonard, 2007; Leadley et al., 2000; Roberts and Leonard, 1998), and not surprisingly, increased risks of divorce (Ostermann et al., 2005). Unfortunately, drinking histories of first spouses were not available for individuals reporting repartnering following separation, divorce, or widowhood. However, in follow-up analyses of ever-married individuals, inclusion of 
current or former spouse history of heavy drinking did little to reduce the magnitude of $\mathrm{AD}$ associations with either onset or survival of first marriages (data not shown).

Regardless of mechanism, genetic risks appear to play an important role, especially for women. From analyses of twin pairs, we observed heritable sources of covariation between $\mathrm{AD}$ and both marital timing and survival. Results indicate genetic influences contribute to associations between $\mathrm{AD}$ and marital delay for women, particularly during early risk periods, consistent with phenotypic observations. For men, heritable covariation between $\mathrm{AD}$ and marital onset was nonsignificant, although confidence intervals were wide so as not to preclude the possibility. For both women and men, genetic influences contributed to associations between $\mathrm{AD}$ and marital survival. For women, heritable covariation with early separation was found regardless of risk period and for men, during later risk periods.

What underlies genetic results? Among likely candidates are a range of inherited traits, including comorbid psychopathology. Shared genes account at least partially for associations between personality and both AD (Slutske et al., 2002) and marital status (Jockin et al., 1996; Johnson et al., 2004). Genetic covariation between $\mathrm{AD}$ and depression has also been reported (Fu et al., 2002; Prescott et al., 2000). Although a genetically informed analysis of depression and marital status has yet to be published, relationships between depression and both never marrying and marital instability have long been documented (Horwitz et al., 1996; Waite, 1995).

Although ours is the first genetically informed analysis of AD effects on timing of marital transitions, we acknowledge several limitations, including reliance on retrospective reports for $\mathrm{AD}$ especially. We also know little regarding the role of remission. In this study, history of AD was analyzed conditioned on three or more AD symptoms experienced within a 12-month period either prior to or at the same time as marital onset or separation. Although effects of AD on marital onset for men reduced to nonsignificance in the presence of control variables, we cannot say that active $\mathrm{AD}$ has no impact on likelihood of marriage. A similar argument can be made for $\mathrm{AD}$ effects for women in models of marital survival. It is certainly likely that individuals who are actively dependent, compared to those in remission, are at much higher risk for both marital delay and subsequent separation.

There are also limits to the generalizability of findings. First, our sample was drawn from an adult cohort of Australian twins, born between 1893 and 1964, many of whom were coming of age during a socially conservative era, when marriage was more common, especially at younger ages. Cohabitation without marriage (or the common-law equivalent) is increasingly common in Australia today (ABS, 2009). Although some researchers (e.g., Horwitz and White, 1998) have found that both women and men who cohabitate report more alcohol problems, compared to married women and men, it is largely unknown whether differences between marriage forms are important. Furthermore, prevalence of marital separation or divorce is very low in this cohort owing in part to restrictive divorce laws prior to 1975 . Whether AD contributes to delay in onset of subsequent marriages also remains unknown. Thus, the present findings require replication in a younger sample, where marriage may be less common and differences associated with nonmarital cohabitation or remarriage can be explored. Although data on AD from a younger cohort of twins born 1964 to 1971 is available, as of last assessment (see Heath et al., 2001; Knopik et al., 2006), the majority remain either unmarried or noncohabiting (Waldron et al., 2009). Follow-up of this cohort will be important for purposes of replication, but also generalization of findings.

In addition, it is possible that observed patterns differ for populations other than our predominantly Caucasian sample. This is especially true given differences by race in risk for substance use or disorder, including $\mathrm{AD}$, with prevalence often lower among African Americans (Grant, 1997; Grant and Dawson, 1997; Hasin et al., 2007). Likelihood of marriage and subsequent separation differs by race as well (U.S. Census Bureau, 2010). Cross-national differences are also possible, with onset of marriage and marriage-like relationships varying widely even among developed countries (Corijn and Klijzing, 2001; Fussell and Gauthier, 2005). The same may be true of $\mathrm{AD}$, although international comparisons of $\mathrm{AD}$ prevalence are difficult because of diagnostic differences and differences in whether prevalence for lifetime versus past year prevalence is reported (WHO, 2004).

Despite limitations, the present study contributes to current understanding of the relationship between marriage and alcohol involvement by extending previous research to examine AD associations with both onset and survival of first marriage, including tests of heritable covariation. Results confirm the importance of $\mathrm{AD}$ as a moderate to strong predictor of both marital delay and early separation, with genetic influences contributing to observed relationships. To better understand the nature of $\mathrm{AD}$ differences in timing of marital transitions, additional research on correlated genetic as well as environmental risks is required. Studies including timevarying comorbid psychopathology as well as personality may be particularly informative, as may studies of other substance use or disorder. Although regular smoking was only weakly related to marital timing, the role of comorbid illicit drug use remains unknown.

\section{ACKNOWLEDGMENTS}

This work was supported by NIAAA grants AA07728, AA11998, AA15210, and AA17688; NICHD grant HD52543; and NIDA grant DA023696.

\section{REFERENCES}

Agrawal A, Heath AC, Grant JD, Pergadia ML, Statham DJ, Bucholz KK, Martin NG, Madden PAF (2006) Assortative mating for cigarette smoking and for alcohol consumption in female Australian twins and their spouses. Behav Genet 36:553-566. 
Australian Bureau of Statistics [ABS] (2009) Australian Social Trends 2009. Cat No. 4102.0. ABS, Canberra, Australia.

Bachman JG, Wadsworth KN, O’Malley PM, Johnston LD, Schulenberg JE (1997a) Smoking, Drinking, and Drug Use in Young Adulthood: The Impacts of New Freedoms and NEW Responsibilities. Lawrence Erlbaum Associates Mahwah, NJ.

Bachman JG, Wadsworth KN, O'Malley PM, Schulenberg J, Johnston LD (1997b) Marriage, divorce, and parenthood during the transition to young adulthood: impacts on drug use and abuse, in Health Risks and Developmental Transitions During Adolescence (Schulenberg J, Maggs JL eds), pp. 246-279. Cambridge University Press, New York, NY.

Bucholz KK, Cadoret R, Cloninger CR, Dinwiddie SH, Hesselbrock VM, Nurnberger JI, Reich T, Schmidt I, Schuckit MA (1994) A new, semistructured psychiatric interview for use in genetic-linkage studies - a report on the reliability of the SSAGA. J Stud Alcohol 55:149-158.

Bulmer MG (1970) The Biology of Twinning in Man. Clarendon Press, Oxford.

Caces MF, Harford TC, Williams GD, Hanna EZ (1999) Alcohol consumption and divorce rates in the United States. J Stud Alcohol 60:647652.

Caetano R, Clark CL (1998) Trends in alcohol consumption patterns among whites, blacks and Hispanics: 1984 and 1995. J Stud Alcohol 59: 659-668.

Chassin L, Presson CC, Sherman SJ, Edwards DA (1992) The natural-history of cigarette-smoking and young-adult social roles. J Health Soc Behav 33:328-347.

Cherlin A (1977) Effect of children on marital dissolution. Demography 14:265-272.

Chilcoat HD, Breslau N (1996) Alcohol disorders in young adulthood: effects of transitions into adult roles. J Health Soc Behav 37:339-349.

Cleves M, Gould WW, Gutierrez RG (2004) Introduction to Survival Data Analysis with Stata, revised edition. Stata Press, College Station, TX.

Collins RL, Ellickson PL, Klein DJ (2007) The role of substance use in young adult divorce. Addiction 102:786-794.

Corijn M, Klijzing E (2001) Transitions to Adulthood in Europe. Kluwer Academic Publishers, Dordrecht.

Cox DR (1972) Regression models and life tables (with discussion). J R Stat Soc Series B Stat Methodol 34:187-220.

Curran PJ, Muthen BO, Harford TC (1998) The influence of changes in marital status on developmental trajectories of alcohol use in young adults. J Stud Alcohol 59:647-658.

Demers A, Bisson J, Palluy J (1999) Wives' convergence with their husbands' alcohol use: social conditions as mediators. J Stud Alcohol 60:368-377.

Donaldson M (2004) A Question of Fault: A Short History of Australian Divorce Law Since 1959. Research Note no. 38 2003-04. Department of the Parliamentary Library, Canberra, ACT.

Efron B (1977) The efficiency of Cox's likelihood function for censored data. J Am Stat Assoc 72:557-565.

Emanuele MA, Wezeman F, Emanuele NV (2002) Alcohol's effects on female reproductive function. Alcohol Res Health 26:274-281.

Forthofer MS, Kessler RC, Story AL, Gotlib IH (1996) The effects of psychiatric disorders on the probability and timing of first marriage. J Health Soc Behav 37:121-132.

Fu HS, Goldman N (1996) Incorporating health into models of marriage choice: demographic and sociological perspectives. J Marriage Fam 58:740758.

Fu HS, Goldman N (2000) The association between health-related behaviours and the risk of divorce in the USA. J Biosoc Sci 32:63-88.

Fu Q, Heath AC, Bucholz KK, Nelson E, Goldberg J, Lyons MJ, True WR, Jacob T, Tsuang MT, Eisen SA (2002) Shared genetic risk of major depression, alcohol dependence, and marijuana dependence: contribution of antisocial personality disorder in men. Arch Gen Psychiatry 59:11251132.

Fussell E, Gauthier A (2005) American women's transition to adulthood in comparative perspective, in On the Frontier of Adulthood: Theory, Research, and Public Policy (Settersten RA, Furstenberg FF, Rumbaut RG eds), pp 76-109. University of Chicago Press, Chicago, IL.
Grambsch PM, Therneau TM (1994) Proportional hazards tests and diagnostics based on weighted residuals. Biometrika 81:515-526.

Grant BF (1997) Prevalence and correlates of alcohol use and DSM-IV alcohol dependence in the United States: results of the National Longitudinal Alcohol Epidemiologic Survey. J Stud Alcohol 58:464 473.

Grant BF, Dawson DA (1997) Age at onset of alcohol use and its association with DSM-IV alcohol abuse and dependence: results from the National Longitudinal Alcohol Epidemiologic Survey. J Subst Abuse 9: 103-110.

Grant JD, Heath AC, Bucholz KK, Madden PAF, Agrawal A, Statham DJ, Martin NG (2007) Spousal concordance for alcohol dependence: evidence for assortative mating or spousal interaction effects? Alcohol Clin Exp Res 31:717-728.

Hajema KJ, Knibbe RA (1998) Changes in social roles as predictors of changes in drinking behaviour. Addiction 93:1717-1727.

Hanna EZ, Faden VB, Harford TC (1993) Marriage: does it protect young women from alcoholism? J Subst Abuse 5:1-14.

Harford TC, Hanna EZ, Faden VB (1994) The long- and short-term effects of marriage on drinking. J Subst Abuse 6:209-217.

Hasin DS, Stinson FS, Ogburn E, Grant BF (2007) Prevalence, correlates, disability, and comorbidity of DSM-IV alcohol abuse and dependence in the United States - results from the National Epidemiologic Survey on Alcohol and Related Conditions. Arch Gen Psychiatry 64:830-842.

Heath AC, Bucholz KK, Madden PAF, Dinwiddie SH, Slutske WS, Bierut LJ, Statham DJ, Dunne MP, Whitfield JB, Martin NG (1997) Genetic and environmental contributions to alcohol dependence risk in a national twin sample: consistency of findings in women and men. Psychol Med 27:13811396.

Heath AC, Howells W, Kirk KM, Madden PA, Bucholz KK, Nelson EC, Slutske WS, Statham DJ, Martin NG (2001) Predictors of non-response to a questionnaire survey of a volunteer twin panel: findings from the Australian 1989 twin cohort. Twin Res 4:73-80.

Hesselbrock M, Easton C, Bucholz KK, Schuckit M, Hesselbrock V (1999) A validity study of the SSAGA - a comparison with the SCAN. Addiction 94:1361-1370.

Homish GG, Leonard KE (2007) The drinking partnership and marital satisfaction: the longitudinal influence of discrepant drinking. J Consult Clin Psychol 75:43-51.

Horwitz AV, White HR (1998) The relationship of cohabitation and mental health: a study of a young adult cohort. J Marriage Fam 60:505514.

Horwitz AV, White HR, Howell-White S (1996) Becoming married and mental health: a longitudinal study of a cohort of young adults. J Marriage Fam 58:895-907.

Jardine R, Martin NG (1984) Causes of variation in drinking habits in a large twin sample. Acta Genet Med Gemellol (Roma) 33:435-450.

Jockin V, McGue M, Lykken DT (1996) Personality and divorce: a genetic analysis. J Pers Soc Psychol 71:288-299.

Johnson W, McGue M, Krueger RF, Bouchard TJ Jr (2004) Marriage and personality: a genetic analysis. J Pers Soc Psychol 86:285-294.

Kaplan EL, Meier P (1958) Nonparametric-estimation from incomplete observations. J Am Stat Assoc 53:457-481.

Kendler KS, Neale MC, Heath AC, Kessler RC, Eaves LJ (1994) A twinfamily study of alcoholism in women. Am J Psychiatry 151:707-715.

Kessler RC, Mcgonagle KA, Zhao SY, Nelson CB, Hughes M, Eshleman S, Wittchen HU, Kendler KS (1994) Lifetime and 12-month prevalence of DSM-III-R psychiatric-disorders in the United-States - results from the National-Comorbidity-Survey. Arch Gen Psychiatry 51:8-19.

Kessler RC, Walters EE, Forthofer MS (1998) The social consequences of psychiatric disorders, III: probability of marital stability. Am J Psychiatry 155:1092-1096.

Knopik VS, Heath AC, Jacob T, Slutske WS, Bucholz KK, Madden PAF, Waldron M, Martin NG (2006) Maternal alcohol use disorder and offspring ADHD: disentangling genetic and environmental effects using a children-oftwins design. Psychol Med 36:1461-1471.

Labouvie E (1996) Maturing out of substance use: selection and self-correction. J Drug Issues 26:457-476. 
Leadley K, Clark CL, Caetano R (2000) Couples' drinking patterns, intimate partner violence, and alcohol-related partnership problems. J Subst Abuse 11:253-263.

Leonard KE, Eiden RD (1999) Husbands and wives drinking: Unilateral or bilateral influences among newlyweds in a general population sample. J Stud Alcohol 13:130-138.

Leonard KE, Eiden RD (2007) Marital and family processes in the context of alcohol use and alcohol disorders. Annu Rev Clin Psychol 3:285-310.

Leonard KE, Mudar P (2004) Husbands' influence on wives' drinking: testing a relationship motivation model in the early years of marriage. Psychol Addict Behav 18:340-349.

Leonard KE, Rothbard JC (1999) Alcohol and the marriage effect. J Stud Alcohol Suppl 13:139-146.

Magura M, Shapiro E (1988) Alcohol-consumption and divorce - which causes which. J Divorce 12:127-136.

Marshal MP (2003) For better or for worse? The effects of alcohol use on marital functioning. Clin Psychol Rev 23:959-997.

Martin NG (1975) The inheritance of scholastic abilities in a sample of twins. II. Genetical analysis of examinations results. Ann Hum Genet 39:219229.

Martin NG, Oakeshott JG, Gibson JB, Starmer GA, Perl J, Wilks AV (1985a) A twin study of psychomotor and physiological responses to an acute dose of alcohol. Behav Genet 15:305-347.

Martin NG, Perl J, Oakeshott JG, Gibson JB, Starmer GA, Wilks AV (1985b) A twin study of ethanol metabolism. Behav Genet 15:93-109.

Martino SC, Collins RL, Ellickson PL (2004) Substance use and early marriage. J Marriage Fam 66:244-257.

McGue M (1994) Genes, environment and the etiology of alcoholism, in The Development of Alcohol Problems: Exploring the Biopsychosocial Matrix of Risk (Costello CG ed.), pp. 1-40. National Institute on Alcohol Abuse and Alcoholism, Washington, DC.

Mcgue M, Lykken DT (1992) Genetic influence on risk of divorce. Psychol Sci 3:368-373.

Miller-Tutzauer C, Leonard KE, Windle M (1991) Marriage and alcohol-use - a longitudinal-study of maturing out. J Stud Alcohol 52:434-440.

Moore KA, Waite LJ (1981) Marital dissolution, early motherhood and early marriage. Soc Forces 60:20-40.

Newcomb MD, Bentler PM (1985) The impact of high-school substance use on choice of young-adult living environment and career direction. J Drug Educ 15:253-261.

Newcomb MD, Bentler PM (1987) Changes in drug use from high school to young adulthood: effects of living arrangement and current life pursuit. J Appl Dev Psychol 8:221-246.

Nichols RC, Bilbro WC Jr (1966) The diagnosis of twin zygosity. Acta Genet Stat Med 16:265-275.

Ooki S, Yamada K, Asaka A, Hayakawa K (1990) Zygosity diagnosis of twins by questionnaire. Acta Genet Med Gemellol (Roma) 39:109-115.

Osler M, McGue M, Lund R, Christensen K (2008) Marital status and twins' health and behavior: an analysis of middle-aged Danish twins. Psychosom Med 70:482-487.
Ostermann J, Sloan FA, Taylor DH (2005) Heavy alcohol use and marital dissolution in the USA. Soc Sci Med 61:2304-2316.

Power C, Estaugh V (1990) The role of family formation and dissolution in shaping drinking behavior in early adulthood. Br J Addict 85:521-530.

Power C, Rodgers B, Hope S (1999) Heavy alcohol consumption and marital status: disentangling the relationship in a national study of young adults. Addiction 94:1477-1487.

Prescott CA, Aggen SH, Kendler KS (2000) Sex-specific genetic influences on the comorbidity of alcoholism and major depression in a population-based sample of U.S. twins. Arch Gen Psychiatry 57:803-811.

Prescott CA, Kendler KS (2001) Associations between marital status and alcohol consumption in a longitudinal study of female twins. J Stud Alcohol 62:589-604.

Roberts LJ, Leonard KE (1998) An empirical typology of drinking partnerships and their relationship to marital functioning and drinking consequences. J Marriage Fam 60:515-526.

Slutske WS, Heath AC, Madden PAF, Bucholz KK, Statham DJ, Martin NG (2002) Personality and the genetic risk for alcohol dependence. J Abnorm Psychol 111:124-133.

StataCorp (2005) Stata Statistical Software: Release 8.2. StataCorp LP, College Station, TX.

Temple MT, Fillmore KM, Hartka E, Johnstone B, Leino EV, Motoyoshi M (1991) A metaanalysis of change in marital and employment status as predictors of alcohol-consumption on a typical occasion. Br J Addict 86:12691281.

Trumbetta SL, Markowitz EM, Gottesman II (2007) Marriage and genetic variation across the lifespan: not a steady relationship? Behav Genet 37:362-375.

U.S. Census Bureau (2010) America's Families and Living Arrangements.

Waite LJ (1995) Does marriage matter? Demography, 32:483-507.

Waite LJ, Lillard LA (1991) Children and marital disruption. Am J Sociol 96:930-953.

Waldron M, Heath AC, Bucholz KK, Madden PAF, Martin NG (2008) Alcohol dependence and reproductive onset: findings in two Australian twin cohorts. Alcohol Clin Exp Res 32:1865-1874.

Waldron M, Heath AC, Lynskey MT, Nelson EC, Bucholz KK, Madden PAF, Martin NG (2009) Smoking and illicit drug use associations with early versus delayed reproduction: findings in a young adult cohort of Australian twins. J Stud Alcohol Drugs 70:786-796.

Wilsnack SC, Klassen AD, Schur BE, Wilsnack RW (1991) Predicting onset and chronicity of women's problem drinking: a five-year longitudinal analysis. Am J Public Health 81:305-318.

Wilsnack RW, Wilsnack SC, Klassen AD (1984) Women's drinking and drinking problems: patterns from a 1981 national survey. Am J Public Health 74:1231-1238.

World Health Organization [WHO] (2004) Global Status Report on Alcohol 2004. World Health Organization, Geneva, Switzerland.

Yamaguchi K, Kandel DB (1985) On the resolution of role incompatibility - a life event history analysis of family Roles and marijuana use. Am J Sociol 90:1284-1325. 